\title{
AnAlysts' EARNINGS FORECASTS FOR DAX100 FIRMS DURING THE STOCK MARKET BOOM OF THE 1990S
}

Prof. Dr. Martin Wallmeier (martin.wallmeier@unifr.ch)

Department of Finance and Accounting, University of Fribourg, Avenue de Beauregard 11, CH-1700 Fribourg, Germany

\begin{abstract}
This paper examines the reliability of financial analysts' consensus earnings forecasts in the 1990s. Analysts are often accused of having fuelled the stock market boom with exaggerated evaluations of firms' prospects. However, this criticism primarily refers to the analysts' buy recommendations rather than earnings forecasts. Although biases in earnings forecasts have been reported since the 1980s, a systematic study capturing the period of 'irrational exuberance' until 2000 on the German stock market has not yet been published. Our data set consists of DAX100 firms, leaving out the peculiarities of forecasting earnings (or rather losses) of young technology firms. To evaluate the information content of analysts' forecasts, we confront them with five alternative forecasting models. The empirical results reveal that analysts' forecasts were too optimistic throughout the entire sample period. However, contrary to the increase in stock prices, the optimistic bias has declined over time. If the bias is removed, the analysts' consensus forecasts significantly outperform all other models considered. Thus, the forecasts seem to be informative with respect to earnings differences, even if the market level of earnings is optimistically overstated.
\end{abstract}

\section{Introduction}

The boom in the international stock markets during the 1990s came along with a growing influence of financial analysts. Especially some technology and e-commerce analysts attracted great attention with their supposition that the "internet age" was calling for new, less conservative valuation standards. Referring to such a growth-oriented valuation, many analysts maintained their buy recommendations even when stock prices reached extremely high levels as measured by economic fundamentals.
Later it turned out that some analysts had even deliberately deceived investors.[1]

This experience has turned the public's and the regulators' attention to conflicts of interest that might distort the analysts' predictions.[2] Often, there is a close relationship between the research group and the investment division of a bank. In the past, the bonuses of the analysts often depended on the profit of the investment banking division. The "Chinese Wall" that was meant to create a barrier between investment banking and brokerage seemed to be as permeable as the historical building in China. Under these circumstances, analysts might be under pressure to publish positive reports in order to establish a favourable banking relationship with the management of the respective firms. Besides, analysts have an incentive to induce investors to higher trading volumes in order to generate commission fees. The commissions earned from clients who are provided with research services constitute an indirect form of remuneration. Since buy recommendations are of interest to all investors, whereas sell recommendations can only be followed by those currently holding the stock, analysts will tend to give positive evaluations.

There is convincing evidence of prevailing buy rankings during the boom of the 1990s.[3] The criticism focused on these recommendations. But analysts also express their view about the prospects of a firm by issuing earnings forecasts. On 
the one hand, these are closely related to the investment recommendations since the present value of future residual earnings plus the book value of equity equals the intrinsic stock value.[4] Thus, buy recommendations should be accompanied by optimistic earnings forecasts compared to market expectations. On the other hand, there are several reasons why the conflicts of interest might show up more distinctly in recommendations than in earnings forecasts. Firstly, reported earnings can be expected to be more closely linked to the firm's profitability and less strongly influenced by irrational exuberance. Thus, overly optimistic earnings forecasts will be detected with a high probability at the end of the prediction period, which will supposedly discipline analysts. In contrast, stock price forecasts are more difficult to assess since the result largely depends on the forecast horizon assumed. Secondly, in a stock market boom, it can be rational to buy even at a very high price level. Analysts, for instance, who issued sell recommendations in the second half of the 1990s due to exaggerated stock prices got into trouble when prices departed even further from fundamental values. Thirdly, analysts' earnings forecasts are often regarded as a target for the company's management.[5] To ensure that it does not fall short of this target, management is in general not interested in unrealistically high target earnings. Analysts seeking to improve management access will take this aspect into consideration. Fourthly, internal analyst rankings applied by large investment institutions seem to be primarily based on earnings estimates rather than recommendations.[6] This could create an incentive for analysts to provide accurate forecasts.

For these reasons, the earnings forecasts for the next few years might convey a more realistic impression of the fair value of stocks than the buyor sell recommendations. This raises the question whether earnings forecasts simply reflected the same irrational exuberance as stock prices or whether they were less strongly biased and could have been used by investors as an indication of unjustified price levels.

In this paper, we examine the accuracy of $\mathrm{I} / \mathrm{B} / \mathrm{E} / \mathrm{S}$ consensus forecasts for the time period from 1991 to 2000. We test whether analysts, on average, displayed a particularly high degree of optimism in the second half of the last decade. We also examine firm-specific determinants of forecasting accuracy in order to find out if corrections for the optimistic bias are possible. The knowledge of the relevant determinants is particularly important for investors who restrict themselves to investments in firms with particular characteristics (e.g., large stocks, value stocks).[7] The average error in this subsample might strongly differ from the overall mean.

The study excludes stocks listed on the former Neuer Markt. The latter firms exhibited peculiarities, such as huge losses combined with high market values, which are not examined in this study. It is important to point out that the study does not primarily aim at analyzing the relevance of analysts' potential conflicts of interest. A detailed analysis of this issue would require individual as opposed to consensus analyst forecasts.

The paper is organized as follows. Section 2 briefly reviews the related literature. Section 3 describes the data. In Section 4, we measure the forecasting accuracy and analyze its determinants. Section 5 compares the analysts' forecasts with alternative forecasting models. The paper concludes with a brief summary.

\section{Related Literature}

The most obvious and serious bias in analysts' earnings forecasts that prior research in the U.S. as well as Europe has uncovered is an exaggerated optimism.[8] The mean surprise at the time of earnings publication is typically negative and significant. The contrary result of BROWN (1996) can be attributed to the data set and the short time period under study.[9] The degree of over-optimism appears to be more pronounced for longer 
forecast horizons.[10] Typically, the initially very optimistic forecasts are adjusted downward as time passes.[11] In the U.S., the bias has diminished over time.[12] The over-optimism of analysts may be explained by their conflicts of interest mentioned earlier. Yet, the relative importance of these conflicts is still open to debate, since internal information on business relations of an analyst's employer is usually not available.

HONG/KUBIK (2003) argue that both higher accuracy and more pronounced optimism are favourable for the career outcomes of analysts. The authors find that the relative importance of an optimistic attitude increased during the recent stock market boom. In a study of German companies over six years, LÖFFLER (1998b) compares different explanations for the existence of biases in earnings forecasts. The empirical data are compatible with the hypothesis that analysts are overconfident and perceive the addressees of their forecasts to underreact. In this environment, analysts deliberately deviate from rational expectations in order to better communicate their view of the firms' prospects. CHAN/KARECSKI/LAKONISHOK (2003) find evidence in support of strategic adjustments of analyst forecasts in recent years. Forecasts are adjusted downwards in order to enable management to exceed expectations.[13] To reconcile this argument with the optimistic bias, one might conjecture analysts to gradually lower their initially exaggerated forecasts until they fall below the rational expectations level shortly before the earnings announcement. EASTERWOOD/ NUTT (1999) document that the reactions of analysts are contingent on the type of information they receive.[14] They underreact both to negative information and to abnormally negative previous forecast errors and at the same time overreact both to positive information and to abnormally positive forecast errors.

Several studies investigate which firm-level factors influence the degree of over-optimism. BROWN (1997), HÜFNER/MÖLLER (1997) and HODGKINSON (2001) report a stronger bias for small firms. DAS/LEVINE/SIVARAMAKRISHNAN (1998) find more optimistic forecasts for firms whose earnings are difficult to forecast on the basis of past information, like time-series of earnings. The mean error also seems to be large when analysts disagree about the prospects of a firm so that the dispersion of forecasts is large.[15] Another stream of literature deals with the performance of analysts relative to alternative forecasting models. At the U.S. market and in different European countries, analysts' forecasts of quarterly and annual earnings appear to be more precise than time-series models.[16]

BOLLIGER (2004) and LIM (2001) summarize studies on factors explaining differences in the accuracy of individual analysts' earnings forecasts.[17] CLEMENT (1999) finds that in the U.S., forecasting accuracy is positively related with analysts' experience [18] and the size of their employers and negatively related with the number of firms and industries followed. In a sample of European companies, BOLLIGER (2004) obtains dramatically different results. Surprisingly, the experience of analysts in Europe seems to be negatively correlated with the quality of their forecasts. The study of MCEWEN/HUNTON (1999) highlights differences in the specific use of accounting information. In general, analysts seem to have a tendency to place too much weight on salient information relative to long-term general conditions. DE BONDT/THALER (1990) conclude: "The same pattern of overreaction found in the predictions of naive undergraduates is replicated in the predictions of stock market professionals. Forecasted changes are simply too extreme to be considered rational.' [19] COOPER/DAY/LEWIS (2001) develop a framework to provide an objective assessment of analyst quality. They identify lead analysts and measure the impact of their forecasts on stock prices.

For the German stock market, there are only few studies on the accuracy of analysts' earnings forecasts. In the first comprehensive study, HÜFNER/ MÖLLER (1997) analyzed biases in earnings forecasts and determinants of forecasting accuracy 
for 206 German stocks in the time period from 1980 to 1993. The forecasts were collected from five major German banks. CAPSTAFF/PAUDYAL/ REES (1998) provide additional evidence based on I/B/E/S individual analysts' forecasts over the period from 1987 to 1995. They compare the forecasting accuracy of German firms with previous results for the U.K.

Our paper contributes to the literature in the following ways. We extend the studies by HÜFNER/ MÖLLER (1997) and CAPSTAFF/PAUDYAL/ REES (1998) to a more recent time period in order to gain insight into the forecasting accuracy in the peculiar market conditions of the second half of the last decade. We provide a more detailed analysis of firm-level factors of forecasting accuracy and systematically compare the analysts' forecasts with alternative forecasting models. The overall objective is to provide relevant information for evaluating the usefulness and quality of analysts' forecasts for German firms.

\section{Data and Definitions}

Our data base consists of the I/B/E/S-Summary History over the time period 1991-2000.[20] I/B/ $\mathrm{E} / \mathrm{S}$ gathers annual earnings forecasts from a large number of banks and brokerage houses all over the world. The Summary History file aggregates all forecasts generated by analysts of the same company at a given point in time. Each data set consists of the company analyzed, the time of prediction, the forecast period (fiscal year), the number of available forecasts and the parameters mean, median, standard deviation, minimum, and maximum of the distribution of forecasts. As usual, we refer to the median instead of the mean as consensus forecast in order to minimize the influence of extreme input data. The inputs are updated every month. Individual analyst forecasts are not available for this study.

We focus on German stocks that are part of the DAX100 index. To avoid a look back or survivor- ship bias, we keep track of the changing composition of the index. At each time of prediction, the respective DAX100 companies are included in the analysis. We exclude data sets with less than three inputs underlying the consensus forecast. All forecasted and reported earnings are calculated on a continuing operations basis. Extra-ordinary charges and other non-operating items are backed out. To this end, most analysts in Germany apply the DVFA/SG scheme.[21,22]

Earnings per share do not seem to be appropriate for cross-sectional comparisons because they depend on the partitioning of equity. With fewer shares outstanding, ceteris paribus, share prices and earnings will be higher and forecasts will thus be subject to greater errors. This scale effect can be neutralized by deflating earnings by the stock price or the book value of equity. Market value deflation renders the time series of forecast errors difficult to interpret since it then depends on general stock market moves.[23] Therefore, we deflate earnings by book value of equity. These deflated earnings form the basis of all further analyses.[24,25] In three cases, negative book values of equity occur (Babcock AG, Holzmann AG, Metallgesellschaft AG) so that the data sets concerned cannot be considered.

As a result of the deflation, forecast errors $F E$ are defined as the difference between forecasted and actual book equity rates of return:

$$
F E_{i, t, T}=\frac{C A F_{i, t, T}-E P S_{i, T}}{E K_{i, T}}
$$

where $C A F_{i, t, T}$ is the consensus forecast of earnings of firm $i$ issued by analysts at time $t$ for fiscal year $T, E P S_{i, T}$ is defined as actual earnings per share of firm $i$ in period $T$, and $E K_{i, T}$ is the per share book value of equity of firm $i$ at the beginning of period $T$.

The cross-sectional mean of forecast errors $M F E$ at a given point in time $t$ can be interpreted as a 
measure of over-optimism $(M F E>0)$ or overpessimism $(M F E<0)$ of analysts:

$M F E_{t, T}=\frac{1}{N_{t, T}} \sum_{i=1}^{N_{t, T}} F E_{i, t, T}$

where $N_{t, T}$ denotes the number of firms for which consensus forecasts for period $T$ are available at time $t$.

As a measure of dispersion, we calculate the cross-sectional standard deviation $S F E$ of forecast errors:

$S F E_{t, T}=\sqrt{\frac{1}{N_{t, T}-1} \sum_{i=1}^{N_{t, T}}\left(F E_{i, t, T}-M F E_{t, T}\right)^{2}}$.

The measures $M F E$ and $S F E$ are only calculated if the relevant input data are available for at least 50 out of 100 index firms.

Table 1 presents descriptive statistics of the deflated (actual) earnings of DAX100 firms in the 1990s.[26] The mean rises substantially during the sample period. It varies between a minimum of $6.8 \%$ and a maximum of $15.2 \%$. The earnings distribution is negatively skewed in most years, which can be partly attributed to earnings management.[27] The kurtosis mostly exceeds 3 . Thus, compared with a normal distribution, a larger fraction of earnings is at the extremes of the distribution.

\section{Accuracy of Analysts' Earnings Forecasts}

\subsection{Optimistic Bias}

In this section, we test the following hypotheses:

Hypothesis 1: The earnings forecasts of financial analysts are, on average, too optimistic, i.e., the consensus forecasts are systematically higher than reported earnings.

Hypothesis 2: The optimistic bias diminishes with a decreasing forecast horizon.

Hypothesis 3: The dispersion of forecast errors diminishes with a decreasing forecast horizon.

These hypotheses are motivated by results of prior research in the U.S. as well as the study of HÜFNER/MÖLLER (1997) in Germany. The first hypothesis states that analysts, on average, did not learn from the experience of overly optimistic forecasts in the years before the time period under study, so that the bias has to be regarded as a rather permanent phenomenon. A persistence of optimism would be indirect evidence of systematic factors pushing analysts towards higher forecasts.

Table 1: Descriptive Statistics of Actual Earnings Deflated by Book Value of Equity

\begin{tabular}{lccccccc}
\hline Year & $N$ & Mean & Skewness & Kurtosis & 25\% Quartile & Median & $75 \%$ Quartile \\
\hline 1991 & 76 & 0.1099 & -0.3152 & 4.9054 & 0.0794 & 0.1147 & 0.1486 \\
1992 & 81 & 0.0840 & -1.3849 & 5.4694 & 0.0474 & 0.0997 & 0.1475 \\
1993 & 90 & 0.0444 & -1.4664 & 3.1015 & 0.0290 & 0.0851 & 0.1368 \\
1994 & 94 & 0.0854 & -1.2993 & 8.5875 & 0.0477 & 0.0916 & 0.1355 \\
1995 & 91 & 0.0688 & -1.6425 & 4.9833 & 0.0558 & 0.0989 & 0.1488 \\
1996 & 90 & 0.1009 & -1.4329 & 5.6410 & 0.0725 & 0.1181 & 0.1547 \\
1997 & 92 & 0.1521 & -0.1209 & 10.0278 & 0.0908 & 0.1428 & 0.2080 \\
1998 & 91 & 0.1502 & -0.2973 & 5.2254 & 0.0941 & 0.1521 & 0.1996 \\
1999 & 93 & 0.1418 & 1.1325 & 11.6080 & 0.0841 & 0.1260 & 0.1814 \\
2000 & 79 & 0.1396 & 0.6973 & 2.1934 & 0.0791 & 0.1162 & 0.1731 \\
\hline
\end{tabular}


The second hypothesis rests on the assumption that analysts correct their overly optimistic (or pessimistic) forecasts when approaching the date of the official announcement of earnings. When more precise information on the firms' profitability becomes available during the year, high-flying earnings expectations have to be abandoned. Otherwise, analysts risk to be unmasked as poor forecasters. Hypothesis 3 states that the forecast accuracy gets better with a shortening of the forecast horizon. This seems obvious, since more information is available to the analysts when coming closer to the earnings release date.

As a first illustration, the scatter-plots in Figure 1 show the levels of $M F E$ and $S F E$ for the last forecast period of the sample period, which is the year 2000. In each case, the X-coordinate displays the forecast horizon, defined as the distance between the time of prediction and the end of the fiscal year to which the forecasts pertain. The forecast horizon is expressed in months. It is evident from the left graph that the analysts were far too optimistic in forecasting the profits of the fiscal year 2000. Thirty months before earnings disclosure, i.e., in mid 1998, analysts forecasted book returns for 2000 that were on average 5\% higher than the book returns actually reported later. The mean forecast error gradually decreases until earnings disclosure. At the beginning of 2000, MFE still amounts to about 1.6\%.[28] Not surprisingly, the plot on the right of Figure 1 reveals a decreasing dispersion of forecast errors when approaching the forecast horizon.

Of course, it is not possible to draw any conclusions from only one year. Such a finding might be caused by an economic shock which diminished the earnings of most firms. But in 8 out of 10 years of the sample period the results are similar. Only in 1997 and 1998 no systematic bias - in either directionwas observed.

Table 2 summarizes the empirical results for forecast horizons of 6,12, and 18 months.[29] With

Figure 1: Mean and Standard Deviation of Forecast Errors in 2000
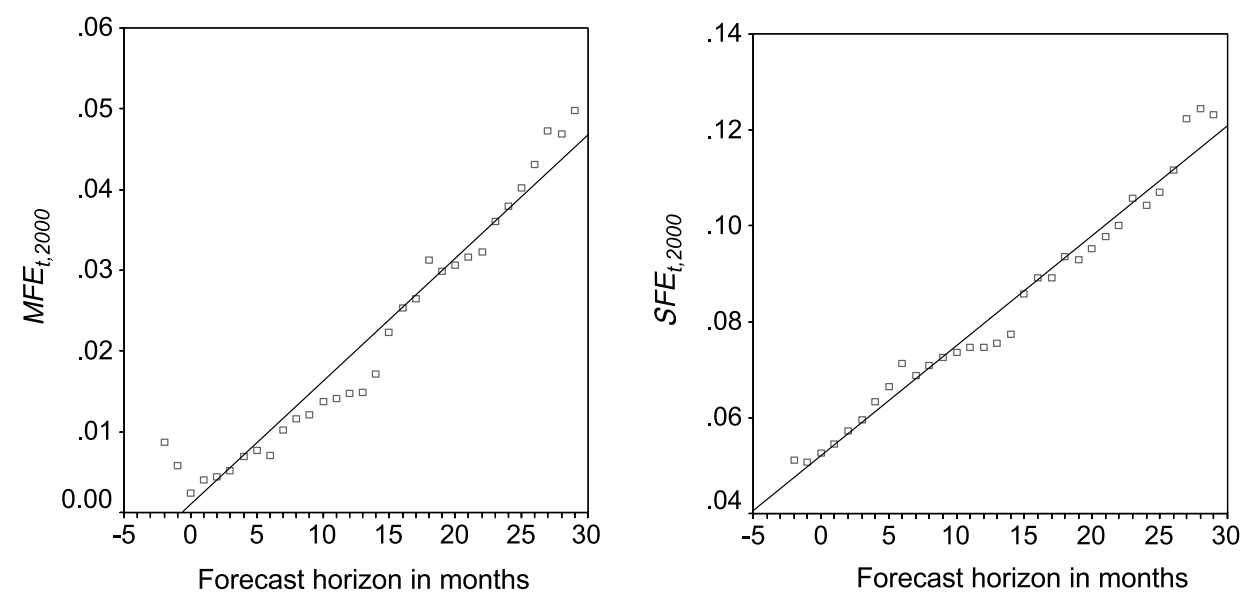
Table 2: Mean Forecast Errors for Different Forecast Horizons

\begin{tabular}{|c|c|c|c|c|c|c|c|c|c|}
\hline \multirow[b]{3}{*}{ Forecast Period } & \multicolumn{9}{|c|}{ Forecast Horizon } \\
\hline & \multicolumn{3}{|c|}{6 Months } & \multicolumn{3}{|c|}{12 Months } & \multicolumn{3}{|c|}{18 Months } \\
\hline & MFE & $N$ & $\%$ Pos. & MFE & $N$ & $\%$ Pos. & MFE & $N$ & $\%$ Pos. \\
\hline 1991 & $2.11 \%{ }^{* *}$ & 80 & 62.5 & $2.73 \%$ ** & 76 & 63.2 & & & \\
\hline 1992 & $4.16 \%$ ** & 89 & 69.7 & $4.75 \%$ ** & 81 & 72.8 & $4.92 \%$ ** & 64 & 75.0 \\
\hline 1993 & $5.79 \%$ ** & 90 & 64.4 & $7.06 \%$ ** & 90 & 68.9 & $10.33 \%$ ** & 83 & 81.9 \\
\hline 1994 & $1.81 \%$ & 96 & 53.1 & $2.02 \%{ }^{*}$ & 94 & 57.4 & $2.64 \%$ ** & 88 & 59.1 \\
\hline 1995 & $4.72 \%$ ** & 92 & 63.0 & $6.07 \%$ ** & 91 & 62.6 & $6.33 \%$ ** & 89 & 56.2 \\
\hline 1996 & $1.44 \%$ & 92 & 50.0 & $3.28 \%$ ** & 90 & 57.8 & $5.55 \%$ ** & 87 & 70.1 \\
\hline 1997 & $-0.55 \%$ & 92 & 40.2 & $-0.65 \%$ & 92 & 37.0 & $-0.30 \%$ & 87 & 42.5 \\
\hline 1998 & $1.37 \% *$ & 94 & 57.4 & $0.69 \%$ & 91 & 49.5 & $0.66 \%$ & 88 & 40.9 \\
\hline 1999 & $2.44 \%{ }^{*}$ & 95 & 60.0 & $3.89 \%$ ** & 93 & 60.2 & $4.53 \%$ ** & 90 & 62.2 \\
\hline 2000 & $1.06 \%$ & 81 & 55.6 & $1.62 \%{ }^{*}$ & 79 & 59.5 & $3.12 \%$ ** & 77 & 63.6 \\
\hline
\end{tabular}

Note:

*Significant at the $5 \%$ level (one-tailed).

${ }^{* *}$ Significant at the $1 \%$ level (one-tailed).

the exception of 1997, all mean forecast errors are positive. The errors increase with a longer forecast horizon, once again with the exception of 1997 and 1998. For most years and forecast horizons, the $M F E$-values are significantly positive at least at the $5 \%$ level. In addition, the fraction of positive forecast errors ( $\%$ pos in Table 2 ) considerably exceeds $50 \%$ in most cases. Thus, there is strong evidence of prevailing over-optimism in the sample period. We conclude that Hypotheses 1 to 3 are strongly supported by the data.

\subsection{Determinants of the Degree of Optimism}

\subsubsection{Hypotheses}

The degree of optimism presumably varies systematically in the cross-section of firms. Knowing which firms are particularly subject to overly optimistic forecasts would help to enlighten the prevailing motives and incentives of analysts. It would also enable investors to correct the bias if they assume that the same motives and incentives will be effective in the future. Therefore, this section deals with the determinants of analysts' predisposition to exaggerated earnings forecasts. As stated earlier, it is important to notice that this analysis is descriptive in nature. Since we restrict ourselves to consensus data, we cannot uncover factors that reflect the individual situation and incentives of an analyst.

The forecast horizon is fixed to twelve months, i.e., we include forecasts launched at the beginning of a fiscal year. This choice can be justified by the fact that the forecasts for the next year usually attract the greatest attention.[30] The following relationships are hypothesized:

Hypothesis 4: The degree of optimism is, on average, higher for growth stocks than for value stocks.

As usual, growth stocks are defined as firms whose stock price reflects a high implicit market expectation of the future growth rate of dividends or earnings. To measure this characteristic, we use the book-to-market ratio of equity. A high ratio indicates a value stock, whereas growth stocks exhibit a low book value of equity per unit of market capitalization. It is well documented that the bookto-market ratio was positively related to mean future stock returns at most international markets during the last decades.[31] Although the reasons for this 
phenomenon are still the subject of an ongoing debate, there is strong support for an explanation based on irrational market behavior.[32] According to this hypothesis, the highest implicit growth rates are unrealistically high and vice versa. When the biased expectations are corrected, the book-tomarket ratios reverse to their cross-sectional mean. Hypothesis 4 states that analysts are mistaken in the same direction as the stock market participants. The experience with the boom of new internet stocks up to 2000 seems to support the presumption of such overreactions especially among growth stocks.

Hypothesis 5: The optimistic bias is more pronounced in the second half of the sample period than in the first one.

The analyst community is often criticized for having fuelled the stock market bubble. Thus, the market mania of the second half of the 1990s should be reflected in particularly optimistic earnings forecasts.

\section{Hypothesis 6 [33]: The degree of optimism is}

- negatively related to firm size (Hypothesis 6a),

- positively related to the stock return volatility (Hypothesis 6b),

- positively related to the standard deviation of forecasts among all forecasts launched for one firm-year combination (Hypothesis 6c).

The extent and the quality of released information generally increase with a higher market capitalization. The investment community concentrates its attention on the DAX30 companies, which are characterized by a large market capitalization and a high trading liquidity. These firms usually organize analyst meetings to elucidate current information about their business outlook. In issuing its own earnings forecasts, the management often transmits a valuable clue to analysts. For these reasons, the optimistic bias is expected to be less pronounced in the group of blue chips among the DAX100 firms.[34] In this study, firm size is measured by the log of market capitalization.

Assuming that an overall tendency towards overly optimistic forecasts exists, we expect the bias to be stronger in an environment of high uncertainty. The overweighting of positive outcomes and vice versa has a larger impact if the possible outcomes are widely dispersed. Higher uncertainty also makes it more difficult to detect biases, so that it protects analysts who are willing to issue positive judgments. As a proxy of forecast uncertainty, we employ the stock return volatility estimated from monthly returns over the last five years. There is an additional reason to expect a positive link between analyst disagreement and biased forecasts according to Hypothesis 6c:[35] Analysts with very low earnings expectations might prefer not to publish them since a negative outlook could be harmful to their career.[36]

Hypothesis 7: The optimistic bias increases with less intensive coverage of firms. The coverage is measured by the number of individual forecasts available for calculating the consensus forecast.

The number of analysts covering a stock is used as a proxy for possible conflicts of interest. If few forecasts are issued, these can be expected to primarily stem from banks with a client relationship with the respective firm. In a larger sample of forecasts, the influence of such banks on the consensus is less strong. One disadvantage of this proxy certainly is that the coverage also depends on the market capitalization, so that it might be impossible to disentangle the relative importance of both variables.

\subsubsection{Empirical Results}

The following empirical analyses focus on a forecast horizon of 12 months, i.e., forecasts are launched at the beginning of each fiscal year.[37,38] We performed all calculations with and without applying a rule for detecting and eliminating outliers. 
Such outliers can, for example, be due to a low book value of equity. Since we divide the earnings per share by book equity, a value near zero will boost deflated earnings. We define a data point as an outlier if either the absolute value of earnings related to book equity is higher than $100 \%$ or absolute forecast errors exceed 50\%. These conditions apply to about $2 \%$ of the data sets. In the following, we report the empirical results after excluding these data. Without elimination of outliers, all results remain practically unchanged. The only differences worth mentioning are slightly higher mean forecast errors and a marginally better performance of analysts compared to other forecast models.

We perform univariate tests of the hypotheses. For this purpose, the pool of sample (time-series and cross-sectional) data is divided into two equally sized groups according to the chosen determinant. In the first case, the sorting is carried out each year. Each year, firms with a low value of the sorting variable are assigned to the first group of pooled data and the remaining stocks are assigned to the second group. In the second case, the sorting is done only once for the pooled data of all firm-year combinations. The hypothesis of normally distributed forecast errors is always rejected at the $1 \%$ significance level. Therefore, we apply the Wilcoxon Rank-sum test to examine whether the null hypothesis of equal medians of forecast errors in the two groups can be rejected at the $1 \%$ or $5 \%$ level. The test statistic of the Wilcoxon
Rank-sum test, which is approximately normally distributed, is shown in Table 3 for the total period as well as two subperiods. The variables are defined as follows:

BEME: Book-to-market ratio of equity,

SUB : Subperiods,

CAP : Logarithm of market capitalization,

VOL : Stock return volatility,

STD : Standard deviation of forecasts,

NUM : Number of forecasts included in the consensus.

The results clearly indicate that Hypotheses 4 and 5 are not supported by the data. Contrary to our expectation, value stocks experienced a significantly more pronounced optimistic bias than growth stocks in the first subperiod (1991 to 1995). This relationship disappears in the second subperiod.[39] We also do not find a rising overall degree of optimism in the sample period. On the contrary, the median of forecast errors observed in the second subperiod is significantly lower than the respective median in the first subperiod. This is compatible with the earlier finding of unbiased forecasts in the years 1997 and 1998. Thus, the degree of optimism diminished while stock prices gradually increased. In view of the stock market mania and the enthusiastic buy recommendations in the second half of the 1990s, the earnings forecasts in this period can be judged as relatively moderate.

Table 3: Determinants of the Degree of Optimistic Bias

\begin{tabular}{|c|c|c|c|c|c|c|}
\hline & \multicolumn{3}{|c|}{ Sorting Each Year } & \multicolumn{3}{|c|}{ Sorting Over All Years } \\
\hline & $1991-1995$ & $1996-2000$ & $1991-2000$ & $1991-1995$ & $1996-2000$ & $1991-2000$ \\
\hline BEME & $2.97^{\star \star}$ & 0.21 & $2.31^{\star}$ & $3.22^{\star \star}$ & 0.51 & $2.55^{\star}$ \\
\hline SUB & - & - & $-2.77^{\star \star}$ & - & - & $-2.77^{\star \star}$ \\
\hline CAP & $-2.79^{\star *}$ & $-3.22^{\star *}$ & $-4.25^{\star \star}$ & $-2.76^{\star \star}$ & $-3.10^{\star *}$ & $-4.40^{\star *}$ \\
\hline VOL & 0.75 & $2.01^{*}$ & $2.13^{*}$ & 1.61 & $3.40^{\star \star}$ & $3.53^{\star \star}$ \\
\hline STD & $4.15^{\star \star}$ & 1.93 & $4.37^{\star \star}$ & $4.09^{\star \star}$ & $2.53^{\star}$ & $4.67^{\star \star}$ \\
\hline NUM & -0.43 & 0.82 & -0.83 & 0.12 & -0.39 & -1.54 \\
\hline
\end{tabular}

Note:

* Significant at the $5 \%$ level; ${ }^{* *}$ significant at the $1 \%$ level (two-tailed). 
The null hypothesis of no difference between the median in the group of smaller stocks and the group of blue chips is always rejected at the $1 \%$ significance level. As expected, the median is lower within the subsample of large capitalization stocks. The second important determinant seems to be the standard deviation of forecasts as a measure of uncertainty. Higher uncertainty is associated with a higher median of forecast errors. The difference between both groups is significant at least at the 5\% level, except for the second subperiod in the case of yearly sorting. Thus, Hypotheses $6 \mathrm{a}$ and $6 \mathrm{c}$ are validated. The stock return volatility points in the same direction as the variable STD, but there is no significant relationship between VOL and forecast errors in the first subperiod. Contrary to Hypothesis 7 , the results do not indicate a uniform and systematic relation between the degree of coverage and the optimistic bias.

The Wilcoxon Rank-sum test requires identical standard deviations of forecast errors in both groups. Since the standard deviation might depend on the same determinants as the degree of optimistic bias, we estimated the standard deviation from sample data of each group and calculated standardized forecast errors. These are defined as forecast errors divided by the sample standard deviation. We then repeated the analysis using standardized forecast errors. The results (not shown here) completely confirm the above findings.

\section{Comparison with Alternative Forecasting Models}

\subsection{Forecasting Models}

To further evaluate the predictive quality of analysts' earnings forecasts, we compare them with five alternative forecasting models. The models employed in U.S. studies are often based on time series of quarterly earnings in the estimation period.[40] Such a comparison is not feasible in Germany since the obligation of listed companies to publish quarterly earnings was not introduced until 2001.[41] Thus, in our sample period, investors had to rely on annual earnings and additional sources of information apart from earnings to build an appropriate forecasting model. Due to this restriction, we do not employ time-series models. As before, all forecasts are deflated by the book value of equity.

Our first model (M1) assumes that current earnings constitute the best forecasts of earnings in the next period:[42]

$$
P_{i, t+1}^{\mathrm{M} 1}=\frac{E P S_{i, t}}{E K_{i, t}}
$$

where $P_{i, t+1}^{\mathrm{M} 1}$ denotes the predicted earnings per share of firm $i$ in period $t+1$ and EPS are realized earnings. Though truly naive in nature, this model turned out to outperform more sophisticated rulebased techniques at the U.S. market.[43] Since we focus on forecasts issued at the beginning of a fiscal year, current earnings (i.e., earnings of the year just completed) have not yet been reported at the time of prediction. As a proxy, we use analysts' consensus estimates of the completed year's earnings. These are generally very close to the earnings actually reported a few weeks later.

Model M1 neglects the empirical observation of a mean-reverting tendency of earnings.[44] Extraordinarily high earnings are generally unsustainable in the long run, and huge losses are often followed by more positive results. The latter observation might be triggered by successful restructuring efforts or by management's ambition to concentrate all foreseeable negative events in one year in order to avoid having to report a sequence of losses. Model M2 draws a rigid conclusion from the mean reversion by setting all forecasts equal to the average of all current earnings in the crosssection of firms:[45]

$$
P_{i, t+1}^{\mathrm{M} 2}=P_{t+1}^{\mathrm{M} 2}=\frac{1}{N_{t}} \sum_{j=1}^{N_{t}} \frac{E P S_{j, t}}{E K_{j, t}}
$$


The third model (M3) attempts to smooth earnings more accurately. The forecasts are taken from a linear regression of analyst's forecasts on previous year's earnings. The regression line

$\frac{C A F_{i, t, t+1}}{E K_{i, t}}=a_{0}+a_{1} \cdot \frac{E P S_{i, t}}{E K_{i, t}}+\varepsilon_{i, t+1}$

generally exhibits a slope coefficient $a_{1}$ smaller than 1 . The slope reflects the analysts' perception of the degree of mean reversion in earnings. The forecasts are calculated as:

$P_{i, t+1}^{\mathrm{M} 3}=\hat{a}_{0}+\hat{a}_{1} \cdot \frac{E P S_{i, t}}{E K_{i, t}}$.

This model is included in order to test whether analysts' forecasts are informative beyond the consideration of this mean tendency of earnings. Our forth model (M4) generates forecasts from capital budgeting theory. Forecasts are defined as earnings required to cover the cost of capital. To estimate such implicit forecasts, a valuation model has to be pre-selected. Our implementation rests on the dividend discount model with a constant growth rate $g$ (Gordon growth model). Clearly, the growth rate is negatively related to the payout ratio since retained earnings are reinvested, generating higher interest earnings and dividends in the future.[46] We use a fictitious payout ratio of $100 \%$, implying that there is no growth of dividends due to interests on previously retained earnings.[47] As a consequence, we chose a relatively low growth rate equal to the expected inflation rate, which we assume to be $2.5 \%$. Therefore, according to model M4, expected earnings in the next period equal the current stock price times the difference between the required rate of return and the rate of perpetual growth:[48]

$$
\begin{aligned}
K_{i, t} & =\frac{E\left[E P S_{i, t+1}\right]}{k_{i}-g} \\
P_{i, t+1}^{M 4} & =\frac{E\left[E P S_{i, t+1}\right]}{E K_{i, t}}=\left(k_{i}-g\right) \cdot \frac{K_{i, t}}{E K_{i, t}},
\end{aligned}
$$

where $K$ denotes the current stock price and $k$ the required rate of return.

The question of which model best explains crosssectional differences between the required rates of stock return is still unresolved. The CAPM of Sharpe, Lintner, and Mossin postulates that beta explains differences in expected returns. Since the 1970s, various studies have disclosed regularities ('anomalies') which seemingly contradict the CAPM.[49] But the variables that seem to contribute to the explanation of expected returns, such as size and book-to-market ratio, lack a solid theoretical foundation.[50] Therefore, we apply the CAPM. We assume a risk-free rate of $4 \%$ and a market risk premium of 3.5\%.[51] The betas are estimated from the time series of daily stock returns during the previous year.

If a firm is not able to cover its required rate of return, the weaknesses of its market position and their determining factors will often persist over more than one year. Model M5 presumes that half of the discrepancy is overcome during the next year. Thus, appropriate forecasts for the next period are set equal to the average of current earnings (M1) and earnings necessary to earn the required rate of return (M4):

$$
P_{i, t+1}^{\mathrm{M} 5}=0.5 \cdot\left(P_{i, t+1}^{\mathrm{M} 1}+P_{i, t+1}^{\mathrm{M} 4}\right) .
$$

\subsection{Methodology}

A specific loss function for examining the impact of forecasting errors cannot be easily specified. Therefore, the forecasting accuracy is measured by the mean squared prediction error (MSE). Given the predicted $\left(P_{i}\right)$ and actual $\left(A_{i}\right)$ earnings, the MSE is defined as:

$M S E=\frac{1}{N} \sum_{i=1}^{N}\left(P_{i}-A_{i}\right)^{2}$. 
To test for statistically different mean squared errors of alternative forecasting models, we compute a $t$-statistic by dividing the MSE-difference by its estimated standard deviation.[52] This test statistic is approximately normally distributed for large samples, assuming that all differences in squared forecast error are drawn from the same population. In the analyses of Section 1 , the large sample assumption could hardly be justified due to the necessity to subdivide the data into two groups. Therefore, we employed a nonparametric test. In this section, the sample is not subdivided so that always more than 75 forecasts are included (see Table 2, forecast horizon 12 months).

The mean squared error can be decomposed into three components for further analysis:[53]

$$
M S E=\underbrace{(P-A)^{2}}_{C 1}+\underbrace{(1-b)^{2} s_{P}^{2}}_{C 2}+\underbrace{\left(1-R^{2}\right) s_{A}^{2}}_{C 3},
$$

where $\bar{P}, \bar{A}$ and $s_{P}^{2}, s_{A}^{2}$ denote, respectively, the means and standard deviations of the predicted and actual earnings; $b$ is the estimated slope coefficient of a regression of actuals on forecasts, and $R^{2}$ is the coefficient of determination of this regression. The first term of equation (11), called error in central tendency $(\mathrm{C} 1)$, represents bias due to misestimating the overall average of reported earnings. The second component $\mathrm{C} 2$ catches errors due to a rotation of the regression line compared to the line of perfect forecasts characterized by $b=1$. A non-zero value of $\mathrm{C} 2$ indicates that high estimates are systematically biased in one direction and low estimates in the other. The third term C3 is a residual component due to imperfect correlation between forecasts and actuals.

In addition, we apply the concept of stochastic dominance to compare different forecast models. [54] We define model $i$ to dominate model $j$ according to first degree stochastic dominance if the cumulative frequency of absolute forecast er- rors below $z \in \mathrm{R}^{+}$is higher for model $i$, regardless of the value of $z$. Formally:

$F_{i}(z) \geq F_{j}(z) \forall z \quad$ and

$F_{i}(z) \neq F_{j}(z)$ for at least one $z$,

where $F_{i}(z)$ is the cumulative frequency distribution of absolute forecast errors generated by model $i$.

Second degree stochastic dominance of model $i$ over model $j$ is fulfilled if the following relationship holds:

$$
\begin{gathered}
\int_{0}^{\mathrm{z}} F_{i}(x) d x \geq \int_{0}^{\mathrm{z}} F_{j}(x) d x \forall z \text { and } \\
F_{i}(z) \neq F_{j}(z) \text { for at least one } z .
\end{gathered}
$$

\subsection{Empirical Results}

The results are summarized in Tables 4 and 5. The tables include, for all forecasting models and sample years, the root mean squared error RMSE, the mean adjusted root mean squared error $(\sqrt{M S E-C 1}=\sqrt{C 2+C 3})$, the ranking of the models in ascending order of RMSE and mean adjusted RMSE, and the slope coefficient $b$ from equation (11). Table 5 also displays the mean absolute error MAE and the decomposition of the mean squared error of the analysts' forecasts.

The analysts' forecasts outperform all other models in five out of nine years of the sample period according to the RMSE-criterion. In two further years they take second place. Only in 1999, the analysts produce less than average results. However, this year is characterized by very similar outcomes of all models with a span of less than 0.02 between the maximum and minimum RMSE.

Model M5 is the only method that does not seem to be inferior to analysts' consensus forecasts. In each year, this model, which averages the forecasts of M1 and M4, turns out to be superior in 


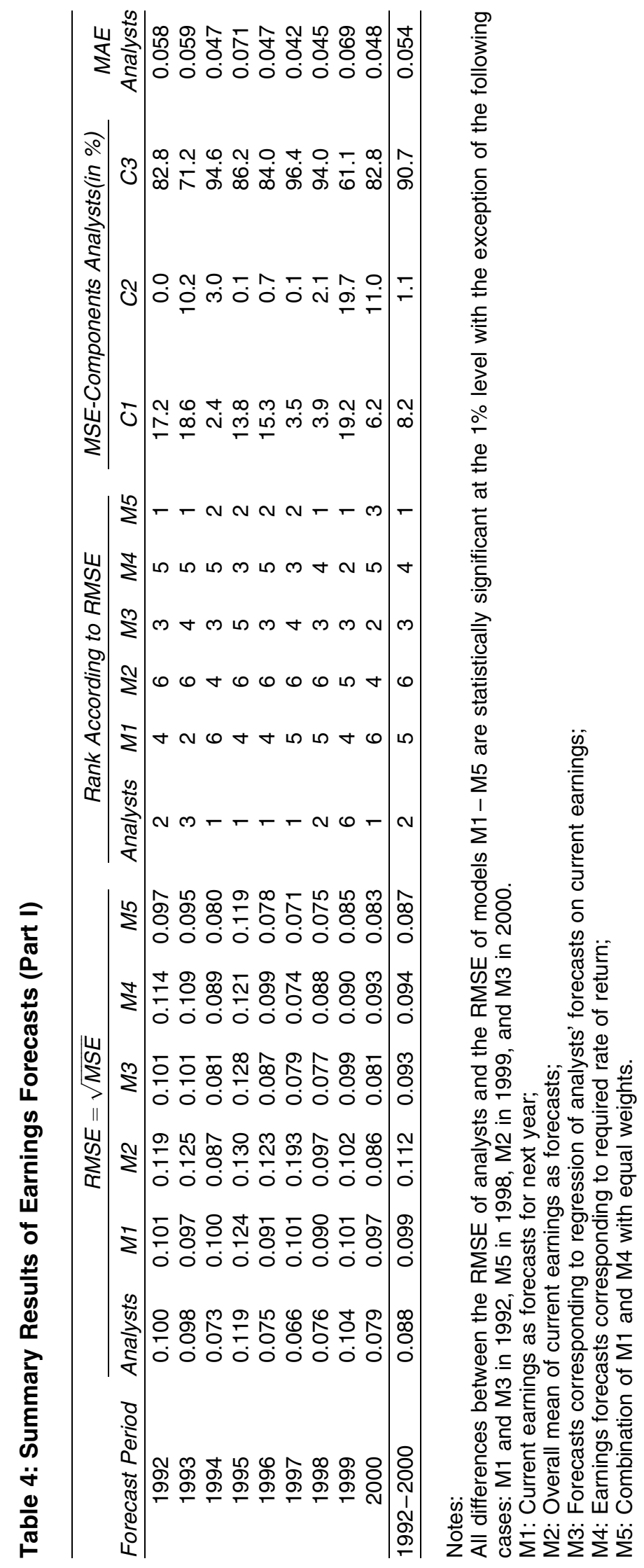




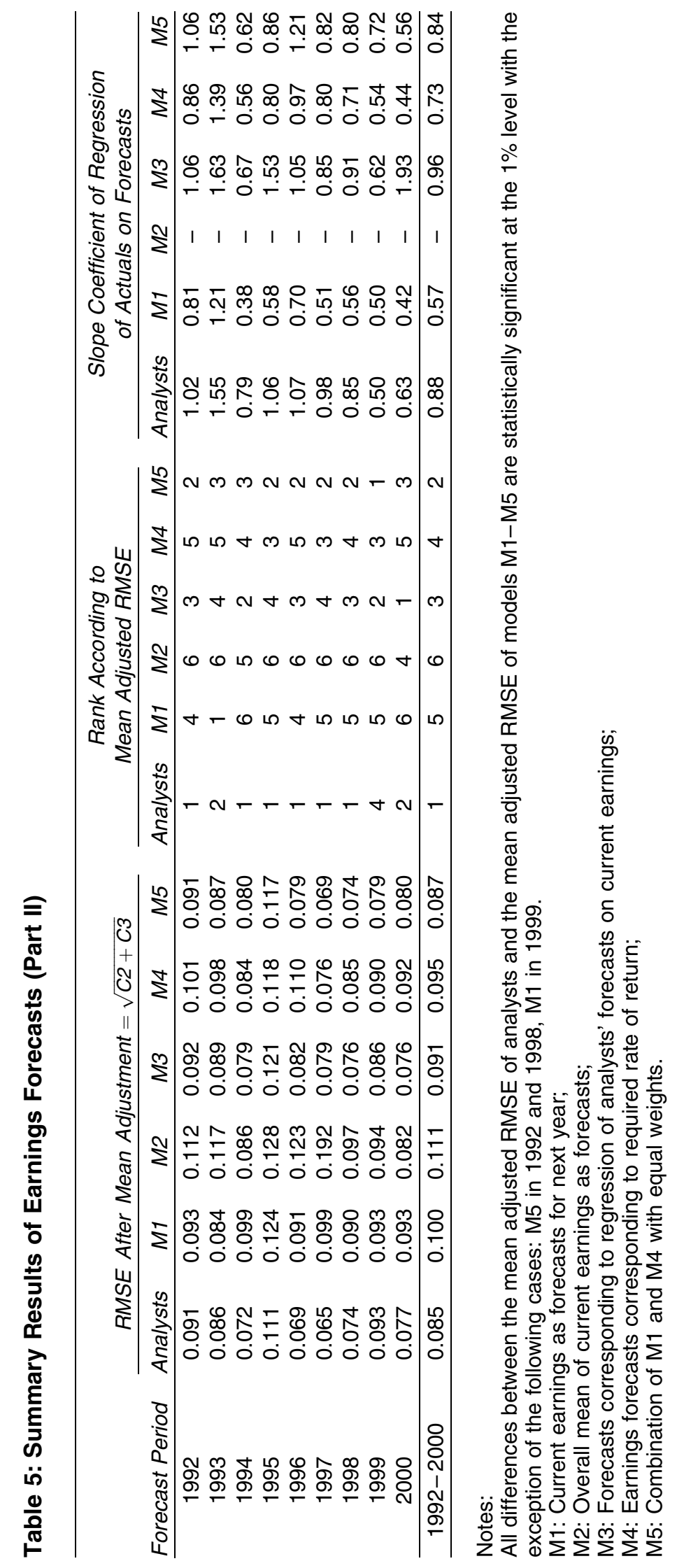


Table 6: Test of Stochastic Dominance of Forecast Models (Total Period, Pooled Data)

\begin{tabular}{|c|c|c|c|c|c|c|c|c|c|c|c|c|}
\hline & \multicolumn{6}{|c|}{ Unadjusted Forecast Errors* } & \multicolumn{6}{|c|}{ Mean Adjusted Forecast Errors ${ }^{* *}$} \\
\hline & Analysts & M1 & M2 & M3 & M4 & M5 & Analysts & M1 & M2 & M3 & M4 & M5 \\
\hline Analysts & - & 2 & 2 & 2 & 2 & & - & & 2 & & 2 & \\
\hline M1 & & - & 2 & & & & & - & 2 & & 2 & \\
\hline M2 & & & - & & & & & & - & & & \\
\hline M3 & & & 1 & - & & & & 1 & & - & & \\
\hline M4 & & & 2 & & - & & & & 2 & & - & \\
\hline M5 & & 1 & 1 & 1 & 2 & - & & 1 & 1 & 2 & 2 & - \\
\hline
\end{tabular}

Notes:

1: Row-model dominates column-model according to first degree stochastic dominance.

2: Row-model dominates column-model according to second degree stochastic dominance.

${ }^{*}: z$ in equations (12) and (13) denotes the absolute value of forecast errors.

${ }^{* *}: z$ in equations (12) and (13) denotes the absolute value of forecast errors shifted such that their mean value is zero.

RMSE to both the M1 and the M4 model. This finding supports the supposition of earnings gradually moving in the direction of their 'equilibrium level' defined by the required rate of return. Apart from the analysts' forecasts, model M1 is the only one that is never stochastically dominated (first or second degree) by any other method (see Table 6).

The relative importance of the first two MSEcomponents in analysts' forecasts strongly varies from year to year. The MSE component C2 is near zero in the total period, while significantly positive in most single years. Apparently, there is an overestimation of high earnings in some years and an underestimation in others, which is also apparent from variations of the slope coefficient $b$ around 1 (see Table 5). In the total period under consideration (pooled data), about $8.6 \%$ of the MSE of analysts' forecasts can be explained by the deviation of the mean (component $\mathrm{C} 1$ ). This conveys an impression of the extent to which improvements in forecasting accuracy for individual stocks might be achieved by correcting the optimistic bias. Removing this bias by mean adjusting the forecasts considerably improves the ranking of analysts. According to the mean adjusted RMSE-criterion, they outperform model M5 in the total period and in eight out of nine single years. The mean adjusted RMSE is of particular interest to investors who generate forecasts of the overall market level of earnings by themselves and consult analysts' forecasts only to learn about expected crosssectional differences in earnings.

The regression model M3 is found in the top ranks in most years, which indicates that considering the mean-reverting tendency of earnings considerably contributes to an improvement of forecasting accuracy. The worst performing model is the overall mean model M2. This extreme form of smoothing clearly generates unreliable earnings forecasts.

\section{Conclusion}

The purpose of this paper was to evaluate the performance of financial analysts in forecasting earnings of German DAX100 firms in the 1990s. The empirical results reveal that the well-known optimistic bias was present throughout the entire time period studied. On average, the analysts successively corrected their overly optimistic forecasts when approaching the forecast horizon. The optimistic bias has declined over time, which seemingly contradicts the impression of enthusiastic buy recommendations maintained during the stock market boom. Given the analysts' consensus forecasts, the high level of stock prices at the peak of the boom could only be justified by assuming 
high growth rates in calculating the terminal value. Thus, the optimism was presumably 'transferred' to more distant periods. The degree of the optimistic bias was, on average, greater for smaller firms and stocks with larger uncertainty.

The fraction of mean squared forecast errors that can be attributed to the optimistic bias varies considerably. In the total sample period, the bias accounts for about $8 \%$ of mean squared errors. The analysts' forecasts turn out to be superior to four of the five alternative forecasting methods considered in this paper. The fifth model, which assumes a gradual shift to an equilibrium earnings level, produces similar results as the analysts. When the optimistic bias is removed, the analysts' consensus forecasts significantly outperform all five benchmark models. Therefore, the forecasts seem to be informative with respect to crosssectional earnings differences, even if the market level of earnings is optimistically overstated.

This paper does not study the relationship between analyst forecasts and stock returns. This seems to be a promising extension for further research since the accuracy of earnings forecasts is expected to be influenced by the market participants' reaction to forecast errors.

\section{Acknowledgements}

Financial support by the Fondation en faveur de la Faculté des sciences économiques et sociales de l'Université de Fribourg is gratefully acknowledged.

\section{ENDNOTES}

[1] After dishonest and illegal practices had been uncovered by the New York State attorney, ten leading investment banks agreed in April 2003 to pay in total 1.4 billion $\$$ to settle the affair out of court. See, e.g., Neue Zürcher Zeitung, April 29, 2003, p. 29.

[2] A detailed description of possible conflicts of interest can be found in HAX (1998) and LÖFFLER (1998a).

[3] As an example, Merrill Lynch was obliged to disclose the detailed structure of its recommendations under the bank's agreement with the New York state attorney. At the end of May 2002, just after the agreement had been reached, Merill Lynch gave nearly 3000 recommendations, more than half of which recommended to buy. Sell recommendations accounted for a fraction of only $6 \%$. Rational investors will take this distribution into account. Buy recommendations will therefore have a lower impact on stock prices than negative outlooks; see the empirical results of GERKE/OERKE (1998).

[4] See, e.g., PENMAN (2001).

[5] See CHAN/KARCESKI/LAKONISHOK (2003), p. 3.

[6] This is not necessarily true for popular rankings. For example, the influential analyst rankings published annually in the Institutional Investor magazine and The Wall Street Journal typically combine stock picking performance with the accuracy of earnings forecasts.

[7] See BROWN (1997).

[8] See, e.g., CAPSTAFF/PAUDYAL/REES (2001), CHOPRA (1998), DREMAN/BERRY (1995), DREMAN (1996), BROWN (1997), KEANE/RUNKLE (1998), HÜFNER/MÖLLER (1997), LÖFFLER (1998b), BROWN (1993).

[9] See BROWN (1997).

[10] See CAPSTAFF/PAUDYAL/REES (1995, 1998, 2001), HUSSAIN (1996), HÜFNER/ MÖLLER (1997), DAS/LEVINE/SIVARAMKRISHNAN (1998), HODGKINSON (2001), CLAUS/ THOMAS (2001). 
[11] See HÜFNER/MÖLLER (1997) and CHOPRA (1998), p. 36.

[12] See BROWN (1997), CHOPRA (1998), CLAUS/THOMAS (2001).

[13] EHRBECK/WALDMANN (1996) test other models of strategic bias due to the attempt of mimicking able forecasters. Yet, the models are rejected empirically.

[14] See also AMIR/GANZACH (1998).

[15] See CHOPRA (1998), p. 38.

[16] See CAPSTAFF/PAUDYAL/REES (1995, 1998, 2001), BROWN (1993), O'BRIEN (1988), BROWN et al. (1987), BROWN/ RICHARDSON/SCHWAGER (1987), CONROY/HARRIS (1987), GIVOLY/LAKONISHOK (1984), FRIED/GIVOLY (1982).

[17] For a more comprehensive overview see BOLLIGER (2004) and LIM (2001).

[18] See also MIKHAIL/WALTHER/WILLIS (2003).

[19] BULKLEY/HARRIS (1997) argue that this might be an important cause of excess volatility in stock prices.

[20] We thank I/B/E/S International Inc. for providing the earnings per share data of the Institutional Brokers Estimate System. The data have been provided as part of a broad academic program to encourage earnings expectations research.

[21] See BUSSE VON COLBE et al. (1996). It is questionable whether DVFA earnings are more informative than reported earnings. HÜFNER/ MÖLLER (2002) find that reported earnings are more closely linked to contemporaneous stock returns than DVFA earnings.

[22] We inspected cases in which there was a particularly large discrepancy between forecasted and reported earnings to make sure that realized earnings are indeed adjusted for extra-ordinary items. Only few errors were detected. The most significant one concerned Fresenius Medical Care in 1999. The I/B/E/S data base displays a realized loss of 3.15 EUR per share, although the DVFA/SG earnings amounted to a profit of $2.15 \$$. The difference was due to expenses incurred to settle litiga- tion out of court. In addition, the profit and loss statement of Fresenius Medical Care was nominated in U.S. dollar instead of Euro.

[23] See BEAVER (1999), p. 38.

[24] For convenience of presentation, we will continue to use the shorter term 'earnings forecasts' although 'forecasts of earnings divided by book equity' would be more precise.

[25] The deflation of earnings is necessary from an academic standpoint, but 'the market' seems to consider earnings per share as the relevant measure. Without deflating earnings, the main conclusions remain valid.

[26] Only firms for which consensus forecasts are available are included.

[27] See the studies on earnings management by DASKE/GEBHARDT/MCLEAY (2003) and BABALYAN (2004).

[28] At the end of the fiscal year (forecast horizon = $0)$, the MFE-value is near zero. Yet, the earnings expectations seem to become more unreliable in the following two months (see left graph of Figure 1, forecast horizons -1 and -2). The reason is that a considerable fraction of analysts cancel their inputs at the balance sheet date. Therefore, the two data points on the left of the graph rest on a smaller number of inputs.

[29] For longer forecast horizons than 18 months, the number of available forecasts strongly diminishes in the first years of the sample period.

[30] We repeated the analysis for forecast horizons of 6 and 18 months and received similar results.

[31] See, e.g., FAMA/FRENCH (1992).

[32] See DANIEL/TITMAN (1997).

[33] This hypothesis is a modified version of hypotheses formulated by HÜFNER/MÖLLER (1997).

[34] In accordance with this general hypothesis, in his study for the U.S., BROWN (1997) finds much smaller forecasting errors for S\&P 500 firms than for other firms.

[35] See SCHERBINA (2004). 
[36] See SCHERBINA (2004) for a comprehensive discussion of this kind of "self-selection", which had first been emphasized by MCNICHOLS/O'BRIEN (1997).

[37] We define the forecast horizon as the balance sheet date instead of the time to publication.

[38] Fiscal years correspond to calendar years for most DAX100 firms. Annual reports with a balance sheet date different from December 31 st are included only if the time difference is at most three months.

[39] This corresponds to findings of MIAN/TEO (2001) at the Japanese market.

[40] See, e.g., O'BRIEN (1988), BROWN et al. (1987), and BROWN (1993) with further references.

[41] The German accounting standard DRS 6 "Zwischenberichterstattung" had to be applied for the first time in the fiscal year beginning after June 30, 2001. Previously, listed firms had been legally required to publish an interim report once a year. See COENENBERG/ ALVAREZ (2002), p. 2759.

[42] This is the "no change prediction" by CAPSTAFF/ PAUDYAL/REES (1998). See also WATTS/LEFTWICH (1977) and FRIED/GIVOLY (1982), who additionally include a growth rate that is assumed to be equal to the average growth in EPS in the past.

[43] See FRIED/GIVOLY (1982) with further references.

[44] FAMA/FRENCH (2000) find strong evidence of mean reversion in profitability.

[45] This model is analogous to the averaging (smoothing) model for correlation matrices tested by ELTON/GRUBER/URICH (1978).

[46] See, e.g., COPELAND/WESTON/SHASTRI (2005), p. 503.

[47] Using the actual payout ratios of individual firms would give the same valuation results if the famous Modigliani-Miller-propositions hold. In this case, changes in payout ratios are perfectly offset by changes in the growth rate.

[48] This model is similar to the first forecasting model of BEAVER/LAMBERT/MORSE (1980) (again without using time series earnings data). It corresponds to the simple forecast SF1 of PENMAN (2001) with an asset base of value $K$.

[49] An overview of the large number of relevant studies can be found in SHANKEN/KOTHARI (2002) and, with an emphasis on the German market, WALLMEIER (2000).

[50] See, e.g., HAUGEN (1995).

[51] CLAUS/THOMAS (2001) report implied costs of capital for various markets that correspond to a market risk premium of about 3 to $4 \%$.

[52] The standard deviation of the mean difference equals the standard deviation of the sample differences divided by the square root of $\left(\mathrm{N}^{2}\right.$ $\mathrm{N}$ ); see ELTON/GRUBER (1988), p. 1659.

[53] See THEIL (1971).

[54] COPELAND/WESTON/SHASTRI (2005) and INGERSOLL (1987), among others, describe the concept of stochastic dominance in the field of portfolio management. 


\section{REFERENCES}

AMIR, E. and Y. GANZACH (1998): "Overreaction and Underreaction in Analysts' Forecasts", Journal of Economic Behavior \& Organization, pp. 333 347.

BABALYAN, L. (2004): Earnings Management by Firms Applying International Financial Reporting Standards: Implications for Valuation, Dissertation University of Fribourg (http://ethesis.unifr.ch/theses/ 2004/BabalyanL/BabalyanL.pdf).

BEAVER, W. H. (1999): "Comments On: An Empirical Assessment of the Residual Income Valuation Model", Journal of Accounting and Economics, pp. 35-42.

BEAVER, W., R. LAMBERT and D. MORSE (1980): "The Information Content of Security Prices", Journal of Accounting and Economics, pp. 3-28.

BOLLIGER, G. (2004): "The Characteristics of Individual Analysts' Forecasts in Europe", Forthcoming Journal of Banking and Finance.

BROWN, L. D. (1993): "Earnings Forecasting Research: Its Implications for Capital Markets Research", International Journal of Forecasting, pp. 295-320.

BROWN, L. D. (1996): "Forecasting Errors and Their Implications for Security Analysis: An Alternative Perspective", Financial Analysts Journal, January/ February, pp. 40-47.

BROWN, L. D. (1997): "Analyst Forecasting Errors: Additional Evidence", Financial Analysts Journal, November/December, pp. 81-88.

BROWN, L. D. et al. (1987): "Security Analyst Superiority Relative to Univariate Time-Series Models in Forecasting Quarterly Earnings", Journal of Accounting and Economics, pp. 61-87.

BROWN, L. D., G. D. RICHARDSON and S. J. SCHWAGER (1987): "An Information Interpretation of Financial Analyst Superiority in Forecasting Earnings", Journal of Accounting Research, pp. $49-67$.

BULKLEY, G. and R. D. HARRIS (1997): "Irrational Analysts' Expectations as a Cause of Excess Volatility in Stock Prices", Economic Journal, pp. 359-371.
BUSSE VON COLBE, W. et al. (1996): DVFA/SG Earnings - Joint Recommendation, 2nd ed., Stuttgart: Schäffer-Poeschel.

CAPSTAFF, J., K. PAUDYAL and W. REES (1995): "The Accuracy and Rationality of Earnings Forecasts by UK Analysts", Journal of Business Finance \& Accounting, pp. 69-87.

CAPSTAFF, J., K. PAUDYAL and W. REES (1998): "Analysts' Forecasts of German Firms' Earnings: A Comparative Analysis", Journal of International Financial Management and Accounting, pp. 83-116. CAPSTAFF, J., K. PAUDYAL and W. REES (2001): "A Comparative Analysis of Earnings Forecasts in Europe", Journal of Business Finance \& Accounting, pp. 531-562.

CHAN, L. K. C., J. KARECSKI and J. LAKONISHOK (2003): Analysts' Conflicts of Interest and Biases in Earnings Forecasts, NBER Working Paper, March. CHOPRA, V. K. (1998): "Why So Much Error in Analysts' Earnings Forecasts?", Financial Analysts Journal, November/December, pp. 35-42.

CLAUS, J. and J. THOMAS (2001): "Equity Premia as Low as Three Percent? Evidence from Analysts' Earnings Forecasts for Domestic and International Stock Markets", Journal of Finance, pp. $1629-1666$.

CLEMENT, M. B. (1999): "Analyst Forecast Accuracy: Do Ability, Resources, and Portfolio Complexity Matter?", Journal of Accounting and Economics, pp. 285-303.

COENENBERG, A. G. and M. ALVAREZ (2002): "Zwischenberichterstattung", in: BALLWIESER W., A. G. COENENBERG and K. V. WYSOCKI (eds.), Handwörterbuch der Rechnungslegung und Prüfung, 3rd ed., Stuttgart: Schäffer-Poeschel, pp. 2758-2774.

CONROY, R. and R. HARRIS (1987): "Consensus Forecasts of Corporate Earnings: Analysts' Forecasts and Time Series Methods", Management Science, pp. 725-738.

COOPER, R. A., T. E. DAY and C. M. LEWIS (2001): "Following the Leader: A Study of Individual Analysts' Earnings Forecasts", Journal of Financial Economics, pp. 383-416. 
COPELAND, T. E., J. F. WESTON and K. SHASTRI (2005): Financial Theory and Corporate Policy, 4th ed., Boston: Pearson/Addison Wesley.

DANIEL, K. and S. TITMAN (1997): "Evidence on the Characteristics of Cross Sectional Variation in Stock Returns", Journal of Finance, pp. 1-33.

DAS, S., C. B. LEVINE and K. SIVARAMKRISHNAN (1998): "Earnings Predictability and Bias in Analysts' Earnings Forecasts", Accounting Review, pp. 277-294.

DASKE, H., G. GEBHARDT and S. MCLEAY (2003): "A Comparative Analysis of the Distribution of Earnings Relative to Targets in the European Union", Working Paper, J.W. Goethe-Universität Frankfurt, May.

DE BONDT, W. F. and R. H. THALER (1990): "Do Security Analysts Overreact?", American Economic Review, pp. 52-57.

DREMAN, D. N. (1996): "Analyst Forecasting Errors", Financial Analysts Journal, May/June, pp. 77-80.

DREMAN, D. N. and M. A. BERRY (1995): "Forecasting Errors and Their Implications for Security Analysis", Financial Analysts Journal, pp. 30-41.

EASTERWOOD, J. C. and S. R. NUTT (1999): "Inefficiency in Analysts' Earnings Forecasts: Systematic Misreaction or Systematic Optimism?", Journal of Finance, pp. 1777-1797.

EHRBECK, T. and R. WALDMANN (1996): "Why are Professional Forecaster Biased? Agency versus Behavioral Explanations", Quarterly Journal of Economics, pp. 21-40.

ELTON, E. J. and M. J. GRUBER (1988): "Time Series Analysis", in: Levine S. N. (ed.), The Financial Analyst's Handbook, 2nd ed., Homewood, IL: Irwin, pp. 1631-1681.

ELTON, E. J., M. J. GRUBER and T. URICH (1978): "Are Betas Best", Journal of Finance, pp. 13751384.

FAMA, E. F. and K. R. FRENCH (1992): "The CrossSection of Expected Stock Returns", Journal of Finance, pp. 427-465.

FAMA, E. F. and K. R. FRENCH (2000): "Forecasting Profitability and Earnings", Journal of Business, pp. 161-175.
FRIED, D. and D. GIVOLY (1982): "Financial Analysts' Forecasts of Earnings", Journal of Accounting and Economics, pp. 85-107.

GERKE, W. and M. OERKE (1998): "Marktbeeinflussung durch Analystenempfehlungen", Zeitschrift für Betriebswirtschaft, Supplement Issue 2, pp. 187-200.

GIVOLY, D. and J. LAKONISHOK (1984): "Properties of Analysts' Forecasts of Earnings: A Review and Analysis", Journal of Accounting Literature, pp. 117-152.

HAUGEN, R. A. (1995): The New Finance, Englewood Cliffs: Prentice Hall.

HAX, G. (1998): Informationsintermediation durch Finanzanalysten, Frankfurt: Peter Lang.

HODGKINSON, L. (2001): "Analysts' Forecasts and the Broker Relationship", Journal of Business Finance \& Accounting, pp. 943-961.

HONG, H. and J. D. KUBIK (2003): "Analyzing the Analysts: Career Concerns and Biased Earnings Forecasts", Journal of Finance, pp. 313-351.

HÜFNER, B. and H. P. MÖLLER (1997): "Erfolge börsennotierter Unternehmen aus der Sicht von Finanzanalysten: Zur Verläßlichkeit von DVFAErgebnissen und deren Prognosen", Zeitschrift für Bankrecht und Bankwirtschaft, pp. 1-14.

HÜFNER, B. and H. P. MÖLLER (2002): "Valuation of German Stocks: Are DVFA/SG Earnings Superior to GAAP Earnings?"; Schmalenbach Business Review, Special Issue 1, pp. 135-170.

HUSSAIN, S. (1996): "Over-reaction by Security Market Analysts: The Impact of Broker Status and Firm Size", Journal of Business Finance \& Accounting, pp. 1223-1244.

INGERSOLL, J. E. (1987): Theory of Financial Decision Making, Savage, MD: Rowman \& Littlefield.

KEANE, M. P. and D. E. RUNKLE (1998): "Are Financial Analysts Forecasts of Corporate Profits Rational", Journal of Political Economy, pp. 768805.

LIM, T. (2001): "Rationality and Analysts' Forecast Bias", Journal of Finance, pp. 369-385.

LÖFFLER, G. (1998a): Der Beitrag von Finanzanalysten zur Informationsverarbeitung. Eine empiri- 
sche Untersuchung für den deutschen Aktienmarkt, Wiesbaden: Gabler.

LÖFFLER, G. (1998b): "Biases in Analyst Forecasts: Cognitive, Strategic or Second-Best?", International Journal of Forecasting, pp. 261-275.

MCEWEN, R. and J.E. HUNTON (1999): "Is Analyst Forecast Accuracy Associated With Accounting Information Use?", Accounting Horizons, pp. 1-16. MCNICHOLS, M. and P. O'BRIEN (1997): "Selfselection and Analyst Coverage", Journal of Accounting Research, pp. 167-199.

MIAN, G. M. and T. G. TEO (2001): "Do Errors in Expectations Explain the Cross-section of Stock Returns?", Working Paper, National University of Singapore, August.

MIKHAIL, M. B., B. R. WALTHER and R. H. WILLIS (2003): "The effect of experience on security analyst underreaction", Journal of Accounting and Economics, pp. 101-116.

O'BRIEN, P.C. (1988): "Analysts' Forecasts as Earnings Expectations", Journal of Accounting and Economics, pp. 53-83.

PENMAN, S. H. (2001): Financial Statement Analysis and Security Valuation, 2nd ed., Boston: McGrawHill.

SCHERBINA, A. (2004): "Analyst Disagreement, Forecast Bias and Stock Returns", Working Paper, Harvard Business School.

SHANKEN, J. and S. P. KOTHARI (2002): "Anomalies and Efficient Portfolio Formation", AIMR monograph.
THEIL, H. (1971): Applied Economic Forecasting, Amsterdam: North-Holland.

WALLMEIER, M. (2000): "Determinanten erwarteter Renditen am deutschen Aktienmarkt - Eine empirische Untersuchung anhand ausgewählter Kennzahlen", Zeitschrift für betriebswirtschaftliche Forschung, pp. 27-57.

WATTS, R. L. and W. LEFTWICH (1977): "The Time Series of Annual Accounting Earnings", Journal of Accounting Research, pp. 253-271.

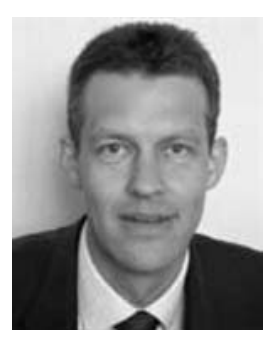

MARTIN WALLMEIER graduated in Business Administration from the University of Münster. He obtained his Ph.D. degree in 1997 and his habilitation in 2002, both from the University of Augsburg. His dissertation and habilitation monograph deal with stock market anomalies and information contained in option prices, respectively. Since October 2002, he is Professor of Finance and Accounting at the Universität Freiburg/Université de Fribourg. He also teaches financial management in various Executive MBA programs and is currently one of the editors of the journal "Die Unternehmung". His primary research interests are in corporate finance and valuation, asset management, option theory and empirical finance. 